\title{
Grammatical Construction of Verb-Particle “off” in English
}

\author{
Astri Arni Murdasari Dewi \\ Language Center, Universitas Muhammadiyah Yogyakarta \\ astriarni@gmail.com
}

\begin{tabular}{|c|c|}
\hline Article Info & ABSTRACT \\
\hline $\begin{array}{l}\text { Article History } \\
\text { - Article Received } \\
1^{\text {st }} \text { March } 2019 \\
\text { - Article Reviewed } \\
29^{\text {th }} \text { March } 2019 \\
\text { - Article Accepted } \\
8^{\text {th }} \text { April } 2019 \\
\text { Keywords } \\
\text { Verb-particle “off" } \\
\text { Construction } \\
\text { alternation } \\
\text { Phrase } \\
\text { Argument's role }\end{array}$ & $\begin{array}{l}\text { This research investigates language phenomenon of verb-particle construction with } \\
\text { particle off in English. This attempts to describe grammatical construction of verb- } \\
\text { particle off. This research was conducted by descriptive-qualitative research method. } \\
\text { The implementation of this method was through a number of stage: data gathering, } \\
\text { analyzing data, and presenting the result of the data analysis. The stage of analyzing } \\
\text { the data was performed by using distributional and identification method with a } \\
\text { number of techniques. This study found that verb-particle construction can be } \\
\text { distinguished from verb-preposition construction by implementing some of } \\
\text { construction alternations, which are (1) noun phrase as object can be put in between } \\
\text { the verb and the particle or after the particle; (2) coordinate noun phrase as object } \\
\text { with the phrasal verb; ( } 3 \text { ) moving noun phrase to the left by itself is acceptable if } \\
\text { without particle, that this indicate the noun phrase is a unit, but moving the particle } \\
\text { and the noun phrase is not acceptable, since they do not form a phrase. The } \\
\text { argument structure of verb-particle with off consists of intransitive, transitive, and } \\
\text { ditransitive. The argument's role of verb-particle off can take action as agent, patient, } \\
\text { and potential agent. }\end{array}$ \\
\hline
\end{tabular}

\section{INTRODUCTION}

One of language unit in English that has variation of form is verb. Unit that can function as a verb is not only a single-form verb, but also verb that consist of several units, such as phrasal verb. The definition of phrasal verb itself is "a type of verb consisting of a sequence of a lexical element plus one or more particles"[1]. Here, the lexical word is a verb which joins together with particle to form a phrasal verb. Therefore, this construction is also called as verbparticle construction. The examples of phrasal verb are such as carry off, carry on, put out, and sit in.

There are a lot of particles in English that can form phrasal verb with verb, and one of them is off. Off has natural sense that is 'away'. Particle is not included in lexical word category of grammatical word category. This is caused by that particle cannot fulfill the requirements as both lexical and grammatical word. The meaning of particle also changes based on the change of the context. Particle off can has meaning that shows location, direction, nor both of them. The examples are,

(1) The officer took off after his men. (OXFL)

(2) The wheels drop off when the aircraft takes off, and the ground crew retrieves them. (OXFL)

(3) The newly launched electronic newspaper has really taken off. (OXFL)

There is a confusion between phrasal verb and prepositional verb since they have similar form. Particle and preposition in some constructions follow the verb, but it has to be noted that preposition actually precede the noun phrase. Both of these constructions are different from the side of grammar and meaning. Therefore, these two construction is needed to be distinguished.

Phrasal verb has idiomatic meaning[2]. The example is in the sentence (3) above, take off has meaning 'become popular'. This meaning cannot be 
derived directly from its parts that are take and off. In the other side, phrasal verb also has aspect meaning[3]. In phrasal verb kick off 'begin or cause something to begin' has aspect meaning that is shown by the feature 'begin'. The other example is such as break off 'to end suddenly' that shows completive meaning by the feature of 'end'. From these fact, it can be seen that there are some meaning classification that can be taken from the meaning of verb-particle off.

Previously, it has been said that verb-particle off has aspectual meaning. This indicates that verbparticle off has the aspectual function. Moreover, the used of phrasal verb commonly is in informal situation as Gelderen[4] says that phrasal verb is a more informal vocabulary choice. Besides that, phrasal verb also has synonym which is more formal vocabulary choice, such as put off that has synonym delay. This relates to the situational function. Furthermore, besides the meaning that is carried by the phrasal verb, some phrasal verbs also show expression speech act. Speech act is utterance that reflect the act of someone[5]. Brush off 'to rudely ignore somebody or refuse to listen to them' shows the expression of refusal.

\section{LITERATURE REVIEW}

Phrasal verb is a unit that consist of a verb and particle[4]. Phrasal verb is not derived from any other construction. In dictionary, phrasal verb is entered in different entry since it has idiosyncratic combination. Celce-Murcia and Larsen-Freeman[3] says that "a phrasal verb is made up by of two (or more) parts that function as a single verb". Even if phrasal verb consists of two parts that are verb and particle, this construction occupies a single function that is as a single verb. Phrasal verb is a single semantic unit, so in order to interpret phrasal verb cannot be done by deriving the element[6].

To distinguish phrasal verb from prepositional verb, there are some grammatical construction that can be used. Gelderen[4] proposes three ways to distinguish both constructions. The first construction is that the object of phrasal verb can be put in the middle of verb and particle or after the particle. Secondly, noun phrase can be coordinated but particle and noun phrase cannot be coordinated together. The last construction is fronting the noun phrase alone in acceptable but fronting the noun phrase and the particle is ungrammatical.
As a verb unit, phrasal verb also has valency. Crystal[1] define valency as a sentence model that has basic elements that are verb and other elements which the number is depend on the ability of verb. The element here refers to the argument, that are argument subject and argument object. From the argument structure it can be seen the semantic role of the argument. Chafe[7] argues that the argument of the verb can be as an agent, a patient, and a potential agent. These semantic roles of the argument are based on the ability of noun to move and to receive the activity of the verb.

Celce-Murcia and Larsen-Freeman[3] say that phrasal verb has idiomatic meaning because it is difficult to figure out the meaning of the verb by combining the separate meaning of its part. The meaning of phrasal verb cannot be predicted from its part and in some cases there are single verb that has same or almost the same meaning[8]. However, the meaning of phrasal verb is not always fully noncompositional, there are some phrasal verb that still has the original meaning of the verb. Therefore, there are a non-compositional phrasal verb and partly compositional phrasal verb.

Besides the idiomatic meaning, phrasal verb also has aspectual meaning. There are four aspects, that are inceptive, continuative, iterative, and completive[3]. Inceptive is a phrasal verb that to signal a beginning state. Continuative is to show the action continues. Iterative indicates the repetition of the action. The last, completive is to show that the action is complete.

As has been mentioned before, that one of the language element is its function. The first function of phrasal verb is related to the aspectual function. Comrie (1976:3) in [9] defines aspect as 'different ways of viewing the internal temporal constituency of a situation'. This function relates to the contribution of the particle and the verb[3]. The second function relates to the used of phrasal verb in some situation. A situation can be one of factors in selecting the code choice or language variation[10]. Commonly, phrasal verb is used in more informal situation[4].

Language is a mean to give expression, so it can be neglected that phrasal verb also can have this function. An utterance can be said has speech act because there is an implicated action and expressive speech act has it. Yule[5] defines expressive utterance as speech act that shows the feeling of the speaker. Therefore, a phrasal verb that has expressive functions means that 


\section{n TION}

phrasal verb has an act that implicates the feeling of the speaker.

\section{METHODOLOGY}

This is a descriptive qualitative research. Qualitative research refers to a research procedure that is used to describe data of language and any things related to language[11]. The data source of this research are gathered from Oxford Advanced Learner's Dictionary-eight edition, Oxford Dictionaries Online and British National Corpus. The data gathering method is observation method. The observation method is conducted without the contribution of the researcher in the language phenomenon[12].

The analysis begins with the analysis of verbparticle construction in order to distinguish between verb-particle construction and prepositional verb. The next analysis is on the valency of the phrasal verbs that are intransitive, transitive, and ditransitive. The semantic role of the argument is also analyzed. The semantic roles of the argument of phrasal verb are agent, patient and potential agent. The semantic classification of the verb-particle off consist of aspectual and non-aspectual. The last is analyzing the function of the verb-particle off.

\section{RESULT AND DISCUSSION}

\section{a. The Definition of Particle Off}

Technical term of particle has been used to refer to a language unit that is never inflected or derivate and especially to units that cannot fit to standard word classification[1]. Particle off is not part of lexical category because particle off does not have lexical meaning and often the meaning changes based on the context and also particle does not have synonym or antonym[4]. Off is also often said has antonym relation with on. There are carry off and carry on, but those form are not antonym or even synonym because they have unrelated meaning. Carry off has meaning 'to win something' while carry on 'to argue or complain noisily'. Off which has antonym is a preposition, such as walk off 'walk away from' and walk on 'walk near to'.

Particle off is also cannot be included in functional or grammatical word. This is because particle does not have any grammatical function. Functional word has function to make lexical category become grammatical or fit together while particle does not have this function[4]. The example $\mathrm{a}$ is used to indicate singularity of a noun and in other side off does not have any kind of this function.

Particle has the same form with preposition that makes both of them are recognize as a same unit. Preposition is part of lexical unit because has antonym. Preposition off has antonym on and the meaning of off is 'removed' and on in 'connected'. Even though, particle off has natural sense that is 'away', the meaning of off is often change depend on its context. For the example is carry off above that does not have any sense of 'away'. Moreover, a language unit, that in this case in particle off, does not belong to preposition category since it is not only express place or direction[4].

Take a look on these sentences below. Off in sentence (1) is a preposition and off in sentence (2) is a particle.

(1) [The slates] FN ffall (V) off the roof (FP)] FV. (BNC)

$$
\text { Det N V Prep Det N }
$$

(2) [The restaurant] $\mathrm{FN}$ [fall off (VF) the standard $(\mathrm{FN})] \mathrm{FV}$. (OXF) Det N V Prt Det N

Those sentence shown in tree diagram will be like the diagram below.
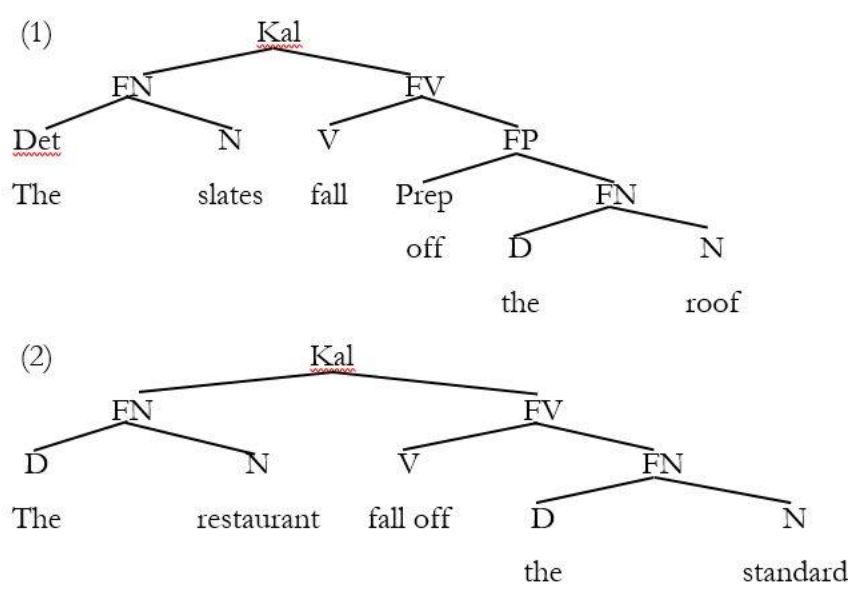

Picture 1 Tree diagram of prepositional verb and verb-particle (Gelderen, 2010:90-91)

In sentence (1), off is preposition since it shows the correlation between noun phrase and the other part of the sentence. As Lilies says in[13] that the definition of preposition is "a closed-class, uninflectable morpheme which shows the relationship between its [noun phrase] object and another word in the sentence". In this sentence preposition off point out the location that is roof before the stales fall. On the other side, off in sentence (2) is a particle since it is not 
always shows any place or direction and has idiomatic meaning. Moreover, off embed with the verb as based on the traditional theory about particle, that particle is a word that is natural unit of verb (Liles, 1987:16 in [13]).

\section{b. Verb-Particle Off Construction}

Most of the phrasal verb has been lexicalized as a semantic unit or syntactic unit, because of the meaning of the phrasal verb cannot be combined form the part that form it[13]. Biber et all (1999:58-59) in [9]) says that phrasal verb is " $[a]$ multi-word lexical unit [as] a sequence of word forms which functions as a single grammatical unit [and which] has become lexicalized". In other words, phrasal verb is a lexical unit that function as single grammatical unit and has been lexicalized with an idiomatic meaning.

Verb-particle is easily confused with prepositional verb since they have same form and moreover particle have the same form also like preposition[4]. For the example is sentence (1) and (2) above. These two construction is different grammatically and semantically. There some grammatical alternation that can be used to differ these two construction. The first is that noun phrase object can be put in between verb and particle or after the particle [4].

(3) [The new factory] FN [cuts off (VF) our view of the hills (FN)] FV. (OXFL) Det Adj $\mathrm{N} V$ Pit Pro N Prep Det N

(4) [They] FN [could not (Mod) get the baby (FN) off (VF) till midnight (FP)] FV.(OXFL)

$\begin{array}{lllll}\text { Pro Mod Neg } & \text { V Det } \mathrm{N} & \text { Prt }\end{array}$

Picture 2. The Structure of off in Gramatical Alternation

In (3), the noun phrase object our view is after the particle off and in (4) the object the baby is between verb get and particle off. Meanwhile, the noun phrase object of preposition cannot be put in between verb and the preposition. As the nature of preposition that is precede the noun phrase.

(5) $[\mathrm{He}] \mathrm{FN}$ [rolled (V) off the bed (FP)] FV. (OXFL)

(6) Pro $\quad$ V Prep Det N
$[$ The coat] FN [slipped (V) off his arms (FP)] FV. (OXFL) Det N V Prep Pro N

Picture 3. The Structure of off Object of Preposition

Sentence (5) and (6) show that the preposition off connects the noun phrase and the verb. Off here shows the previous location of the subject that he is in the bed (5) and the coat is on his arms (6). The changed position of object preposition (he rolled the bed off and the coat slipped his arms off) is unacceptable because of the nature of preposition itself and the noun phrase of the bed and bis arms is the object of preposition not the verb.

The second alternation is that noun phrase object can be coordinated but noun phrase object and particle cannot be coordinated with another noun phrase and particle[4]. The examples are sentence (7) and (8) below.

(7) [Mr. de Klerk] FN [had to (Mod) call off (VF) the rally and a lunch (FN)] FV. (BNC)

(8) ${ }^{*}$ Mr. de Klerk had to call off the rally and Dit Det N Kon Art N

Picture 4. The Other Alternation

The third alternation is fronting the noun phrase object is acceptable while fronting noun phrase object and particle is not[4]. This indicates that verb and particle is a unit, so that cannot be separated by fronting the particle to the beginning of the sentence along with the noun phrase object. The example is the sentence below.

(9) [He] FN [has (Mod) written off (VF) two cars (FN) this years (Adv)] FV.
(OXFL) Mod D Prt Det N Det N
Pro M P It was that two cars he has written off.
(11) It was off two cars he has written.

Picture 5. The Thrid Alternation

On the other side, fronting the preposition and noun phrase is acceptable since preposition is natural unit of noun phrase. The example can be seen in sentence (13) and (14) below.

(13) [Snorts and guffaws] FN [bounce (V) off the walls (FP)] FV. (BNC) $\mathrm{N}$ Kon $\mathrm{N}$ Prep Det N

(14) [Off the walls (FP) snorts and guffaws] FN [bounce] FV.

Prep Det N N Kon N V

Picture 6. The Natural Unit of Noun Phrase

The fronting alternation that is applied on preposition and the noun phrase is not using clause as its final form, while fronting noun phrase object of phrasal verb needs clause as its form because the noun phrase cannot stand alone.

From the grammatical characteristics above, there are at least 80 verb-particle off in English. Then, those verb-particle off will be analyzed relating to the valency of the phrasal verb.

\section{CONCLUSION}

This research finds at least 80 verb-particle off. Verb-particle off is formed by verb and particle off. The Verb-particle off construction is different with verb plus preposition off construction by 
implementing some grammatical alternations that are (1) object noun phrase can be put between verb and particle or after the particle, (2) coordinate the object noun phrase with the phrasal verb, and (3) fronting the object noun phrase by itself is acceptable while fronting object noun phrase and particle is not acceptable. Verb-particle off has the one valency, two valencies, and three valencies. The role semantic of argument of verb-particle off is agent, patient, and potential agent.

\section{REFERENCES}

[1] Crystal, David. 2008. A Dictionary of Linguistics and Phonetics - Sixth Edition. Oxford: Blackwell.

[2] Jackendoff, Ray. 2002. English Particle Construction, the Lexicon, and the Autonomy of Syntax. Dehe, Nicole, Ray Jackendoff, Andrew McIntyre, \& Silke Urban (Eds). 2002. VerbParticle Exploration. Berlin: Mouton de Gruyter.

[3] Celce-Murcia, Marianne \& Diane LarsenFreeman. 1999. The Grammar Book-An ESL/EFL Teacher's Course-Second Edition. Boston: Heinle \& Heinle Publisher.

[4] Gelderen, Elly Van. 2010. An Introduction to the Grammar of English - Revised Edition. Philadelphia: John Benjamins Publishing Company

[5] Yule, George. 1996. Pragmatics. Oxford: Oxford University Press.

[6] Putz, martin. 2007. Linguistics and Applied Linguistics. (page1139-1159). Geeraerts, Dirk \& Hubert Cuyckens (eds). 2007. The Oxford Handbook of Cognitive Linguistics. Oxford. Oxford University Press.

[7] Chafe, Wallace L. 1970. Meaning and the Structure of Language. Chicago: The University of Chicago Press.

[8] Palmer. F.R. 1983. Semantics. Cambridge: Cambridge University Press.

[9] Walkova, Milada. 2013. The Aspectual Function of Particles in Phrasal Verbs. Kosice: MKV Press.

[10] Holmes, Janet. 1995. An Introduction to Sociolinguistics. London: Longman.

[11] Bogdan, Robert C. \& Steven J. Taylor. 1975. Introduction to Qualitative Research Method. New York: John Wiley \& Son.

[12] Kesuma, Tri Mastoyo Jati. 2007. Pengantar (Metode) Penelitian Bahasa. Yogyakarta: Carasvatibooks.
[13] O’Dowd, Elizabeth M. 1998. Prepositions and Particles in English - A Discourse-Functional Account. Oxford: Oxford University Press. 